\title{
VoIP-based Calibration of the DQX Model
}

\author{
Tsiaras, Christos ; Rösch, Manuel ; Stiller, Burkhard
}

DOI: https://doi.org/10.1109/IFIPNetworking.2015.7145309

Posted at the Zurich Open Repository and Archive, University of Zurich

ZORA URL: https://doi.org/10.5167/uzh-116551

Conference or Workshop Item

Supplemental Material

Originally published at:

Tsiaras, Christos; Rösch, Manuel; Stiller, Burkhard (2015). VoIP-based Calibration of the DQX Model. In: IFIP Networking 2015, Toulouse, France, 20 May 2015 - 22 May 2015. IEEE, 1-9.

DOI: https://doi.org/10.1109/IFIPNetworking.2015.7145309 
Access provided by:

MAIN LIBRARY UNIVERSITY OF

ZURICH

Sign Out

\section{VolP-based calibration of the DQX \\ model}

\section{Full Text as PDF}

Full Text in HTML

3

Tsiaras, C. ; Dept. of Inf. (IFI), Univ. of Zurich, Zurich, Switzerland ; Rosch, M. ; Stiller, B.

Author(s)

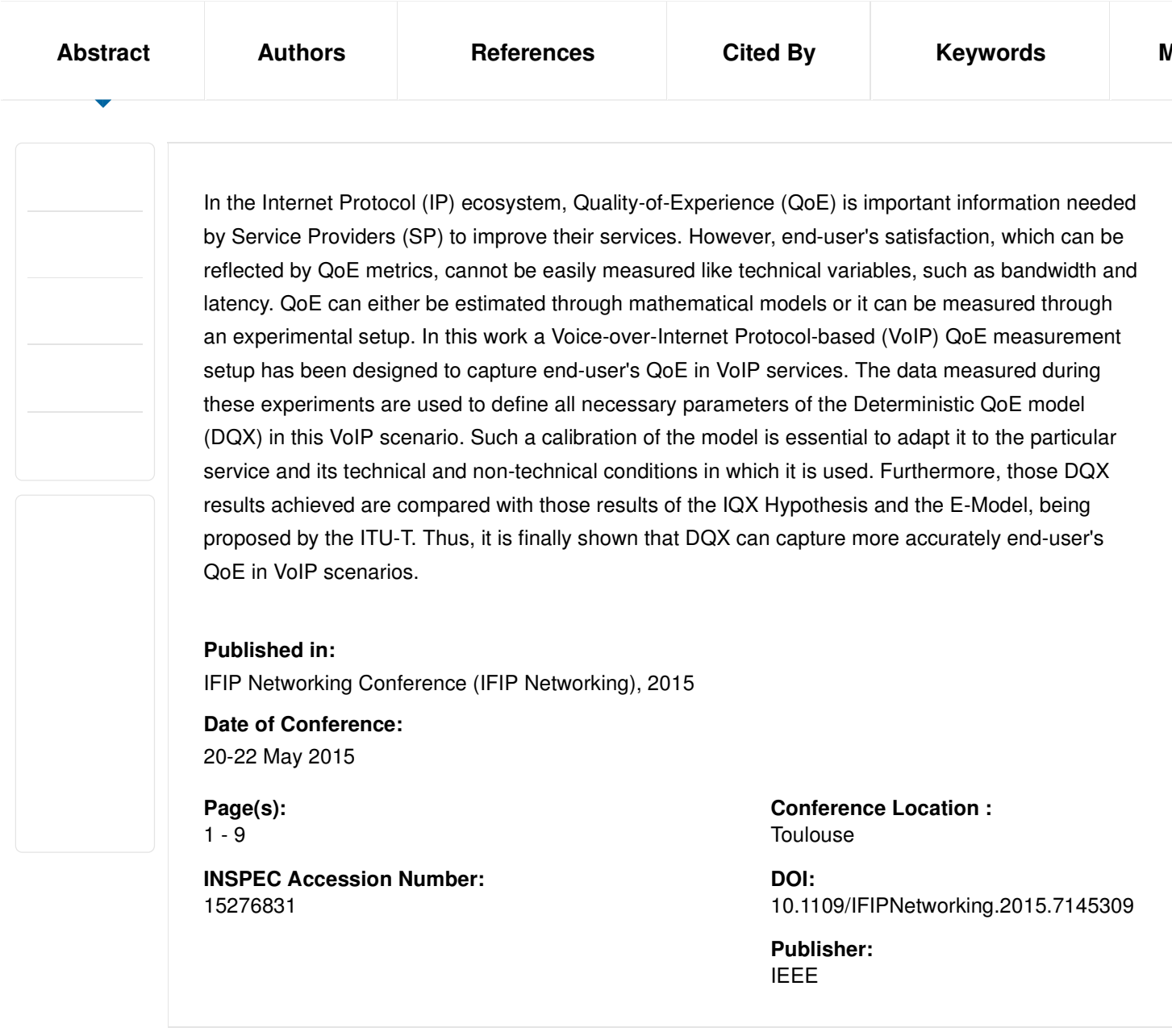

\section{IEEE Account}

" Change Username/Password

"Update Address

Purchase Details
"Payment Options
"Order History
"View Purchased Documents

\section{Profile Information}

"Communications Preferences

"Profession and Education

"Technical Interests

\author{
Need Help? \\ US \& Canada: +1 8006784333 \\ Worldwide: +1 7329810060 \\ Contact \& Support
}

